\title{
A comparative study of central corneal thickness (CCT) and intraocular pressure (IOP) in University of KwaZulu-Natal students of Black and Indian ethnicity*
}

\author{
Z Sardiwalla, D Moodley, T Ndawonde, A Madikizela, N Ngobese, $\mathbf{N}$ Thobela and OA Odun- \\ $\tan *$
}

Discipline of Optometry, School of Health Sciences, University of KwaZulu-Natal, Private Bag x54001, Durban, 4000 South Africa

<oduntanoa@ukzn.ac.za>

Received 6 March 2012; revised version accepted 31 October 2012

\section{Abstract}

This study compared central corneal thickness (CCT) and intra-ocular pressure (IOP) of Black and Indian students from the University of KwaZulu-Natal. Two hundred (100 Black and 100 Indian) participants of both genders aged 18-25 years (mean and standard deviation; $20.1 \pm 1.6$ years) participated in this study. CCT and IOP were measured for the right eye of each participant using a Tono-Pachymeter (NT530P) and a Goldmann applanation tonometer (GAT) respectively. Data was analyzed with descriptive, $t$-test and Pearson's correlation statistics. In the total sample $(N=200)$, the mean CCT value was $519.5 \pm 38.6 \mu \mathrm{m}$ and CCT was higher in the Indians $(526.5 \pm 37.2 \mu \mathrm{m})$ than in the Blacks $(512.4 \pm 38.9 \mu \mathrm{m})(p=0.01)$. Also, it was higher in the females $(522.3 \mu \mathrm{m})$ than in males $(516.7 \mu \mathrm{m})$, but the difference was insignificant $(p$ $=0.07)$. The mean CCT was higher in the Indian males $(520.1 \mu \mathrm{m})$ than in the Black males $(513.2$ $\mu \mathrm{m})$, but the difference was insignificant $(p=0.39)$. However, it was significantly higher in the Indian females $(533 \mu \mathrm{m})$ than in the Black females (511.6 $\mu \mathrm{m})(p=0.003)$. In the total sample, the mean IOP was $14.6 \mathrm{mmHg}$ and IOP was greater in Indians than Blacks (mean $=15.3 \pm 2.9 \mathrm{mmHg}$ and $13.8 \pm$ $2.6 \mathrm{mmHg}$ respectively) $(p=0.01)$. Also, the mean IOP $(N=200)$ value was slightly higher in the females $(14.7 \mathrm{mmHg})$ than in males $(14.5 \mathrm{mmHg})$ $(p=0.51)$. The mean IOP was higher in the Indian males $(15.0 \mathrm{mmHg})$ than in the Black males $(14.0$ mmHg) $(p=0.07)$ and the mean IOP value was higher in the Indian females $(15.7 \mathrm{mmHg})$ than in the Black females $(13.6 \mathrm{mmHg})(p<0.001)$. The higher mean IOP value in the Indian than Black participants was attributed to the higher mean CCT values. A positive, but inconsistent association between CCT and IOP was found in this study, the coefficient in the total sample $(r=0.382, p=$ $0.000)$, in the Blacks $(r=0.196, p=0.05)$ and in Indians $(r=0.498, p=0.000)$. A national population study comparing CCT and IOP in the various South African ethnic groups is recommended. Cognizance of these differences should be taken in the diagnoses of glaucoma in these ethnic groups. (S Afr Optom 2012 71(4) 171-177)

Key words: Central corneal thickness, intraocular pressure, ethnicity and corneal thickness, ethnicity and intraocular pressure.

*Corresponding author: Prof OA Oduntan, Discipline of Optometry, UKZN 


\section{Introduction}

The World Health Organization (WHO) regards glaucoma as the leading cause of irreversible blindness globally ${ }^{1}$. Intraocular pressure (IOP) is associated with glaucoma and corneal thickness has been found to have a significant relationship with IOP in a number of studies ${ }^{2-11}$. However, some authors ${ }^{12}$ have claimed that a linear relationship does not exist between IOP and CCT and a universal algorithm cannot, therefore be used. Also, various studies ${ }^{2-4, ~ 6-10}$ have reported varying CCT values in different race groups. Studies have shown that African Americans and other Black populations have significantly thinner corneas than the Caucasians ${ }^{3,9,10}$. This may result in lower intra-ocular pressure values and delayed diagnosis of glaucoma in the Black population. A report $^{11}$ that the clinical course of glaucoma can be more serious in Blacks (than for their Caucasian counterparts) can perhaps be due to lower IOP in Blacks from their thinner corneas. Gender differences have also been reported in CCT and IOP values ${ }^{2}$, $3,7,9$. No data could be found in the literature regarding ethnic variation in CCT and IOP in a South African population. This study was, therefore conducted to obtain baseline data in non-glaucomatous South African Black and Indian young adult population and to establish if any differences exist in the CCT and IOP of these specific ethnic groups.

\section{Material and Methods}

This study was approved by the Biomedical Research and Ethics Committee, Faculty of Health Sciences, University of KwaZulu-Natal, South Africa and all ethical guidelines were adhered to during and after the study. Sample size was calculated using a sample calculator for comparing the means of two independent groups. A convenient sampling method was used to select the 200 young adult South Africans included in the study. An equal numbers of male and female participants were included. Only participants aged 18-25 years were included because the study focused on university students and this is the common age range. The Black and Indians were chosen as they represent the majority of the population in the study location (UKZN, Westville Campus). Following written informed consent from each participant, slit lamp examination and ophthalmoscopy were conducted to rule out ocular pathology and those with any sign of ocular pathology were excluded. A case history was taken with regard to the use of medications, ocular symptoms, injuries or surgery and contact lens wear. Those with a history of ocular surgery, known allergies to topical anesthetic drugs or those on contraceptives, corticosteroids or other drugs that may influence IOP values were excluded. Contact lens wear is contraindicated for GAT measurement and may influence CCT measurements ${ }^{13}$, therefore contact lens wearers were also excluded from the study.

Central corneal thickness was measured (right eye only) with the non-contact Nidek NT530P Tonopachy ${ }^{\mathrm{TM}}$ and IOP readings were taken with the Goldmann applanation tonometer (Haag-Streit) for the same eyes. The Goldman applanation tonometer is generally regarded as the gold standard for IOP measurement and the Nidek NT530P Tonopachy ${ }^{\mathrm{TM}}$ has been reported to be a reliable alternative; giving precise and repeatable measures of CCT and IOP over a short period of time ${ }^{14}$. To increase reliability of values, recruitment of participants were done randomly with no regard for specific race or gender and values were obtained between $10 \mathrm{am}$ and $5 \mathrm{pm}$ each day. Also, three consecutive IOP and CCT readings each were taken and their averages recorded. Further, the CCT and IOP measurements were taken by one clinician each. Prior to the study, a pilot study was conducted on ten subjects to standardize the procedure. Values from the ten subjects were not included in the study data. Data was analyzed with descriptive, $t$-test and Pearson's correlation statistics of the Statistical Package for Social Sciences (SPSS), Version 18. Normality of distributions of CCT and IOP data was determined with a One-Sample Kolmogorov-Smirnov Test. Means were compared using the independent sample $t$-test and correlation between variables was established with the Pearson's correlation coefficient.

\section{Results}

The ages of the 200 participants ranged from 18 to 25 years (with mean and SD of $20.1 \pm 1.6$ years). The ages of the Black participants were 18 to 25 years $(20.2 \pm 1.7$ years $)$ and the Indians were aged 18 to 24 years $(19.9 \pm 1.4$ years $)$. In the total sam- 
ple $(N=200)$ the CCT ranged from 442 to $642 \mu \mathrm{m}$; mean $=519.5 \pm 38.6 \mu \mathrm{m}$. The mean CCT was higher in the Indians than in the Blacks (See Table 1) $(p=$ 0.01 ). The mean CCT value for was higher in the females than in males ( $N=100$ each) (See Table 2$)$, but the difference was insignificant $(p=0.07)$. The CCT and IOP in relation to gender in each race group are shown in Table 3. The mean CCT value was significantly higher in the Indian females than in the Black females $(p=0.003)$. However, the mean CCT was insignificantly higher in the Indian males compared to the Black males (Table 3) $(p=0.4)$. The mean CCT was higher in Black males 513.2 $\mu \mathrm{m}$ than Black females $(511.6 \mu \mathrm{m}(p=0.83)$, but it was higher in Indian females than males (Table 3$)(p=0.09)$.

The IOP $(N=200)$ ranged from 9 to $22 \mathrm{mmHg}$ (mean $=14.6 \pm 2.8 \mathrm{mmHg}$ ). The distributions are shown in the frequency histograms (Figures 1). The mean IOP was greater in Indians than in blacks (See Table 1) $(p=0.01)$. The range, mean and standard deviation of the male and female IOP are shown in Table 2. The IOP was higher in females than in males, but the difference was not statistically significant $(p=0.51)$. The mean IOP was higher in the Indian males than in the black males $(p=0.07)$ and higher in the Indian females than in the Black females (Table 3) $(p=0.00)$. The mean IOP was higher in Black males than Black females $(p=0.45)$ and in the Indian females than males (Table 3$),(p=0.20)$.

A positive but inconsistent association was found between CCT and IOP, as the association was significant in the total population (Pearson's coefficient $r=0.38, p<0.001)$ and Indians $(r=0.498, p=0.000)$, but not in the Blacks $(r=0.20, p=0.05)$. The scatter plot showing the relationship between CCT and IOP of all the participants $(N=200)$ is shown in Figures 3. The plots showing the relationship between CCT and IOP of the Blacks and Indians are shown in Figures 4 and 5 respectively.

Table 1: Showing the range, mean and standard deviation (SD) of CCT and IOP in the two groups. The mean CCT and IOP values are higher in Indians than in Blacks.

\begin{tabular}{|l|l|l|l|l|}
\hline \multirow{2}{*}{ Statistics } & \multicolumn{2}{|c|}{ CCT $(\boldsymbol{\mu m})$} & \multicolumn{2}{c|}{ IOP $(\mathbf{m m H g})$} \\
\cline { 2 - 5 } & Blacks & Indians & Blacks & Indians \\
\hline Range & $442-642$ & $442-607$ & $9-21$ & $9-22$ \\
\hline Mean & 512.4 & 526.5 & 13.8 & 15.3 \\
\hline SD & 38.9 & 37.2 & 2.6 & 2.9 \\
\hline
\end{tabular}

Table 2: Showing the range, mean and SD for CCT and IOP in relation to gender of the total population; Males $(\mathrm{M}): N=100$ and Females (F): $N=100$.

\begin{tabular}{|l|l|l|l|l|}
\hline \multirow{2}{*}{ Statistics } & \multicolumn{2}{|c|}{ CCT $(\boldsymbol{\mu m})$} & \multicolumn{2}{c|}{ IOP (mmHg) } \\
\cline { 2 - 5 } & $\mathrm{M}$ & $\mathrm{F}$ & $\mathrm{M}$ & $\mathrm{F}$ \\
\hline Range & $442-642$ & $443-607$ & $9-21$ & $9-22$ \\
\hline Mean & 516.7 & 522.3 & 14.5 & 14.7 \\
\hline SD & 40.1 & 37.1 & 2.7 & 3.0 \\
\hline
\end{tabular}


Table 3: Showing the range, mean and SD of CCT and IOP in relation to gender in the two race groups. The mean CCT and IOP values in Indian females are greater than those of Indian males, Black males and Black females.

\begin{tabular}{|l|l|l|l|l|l|l|l|}
\hline Race & Gender & \multicolumn{2}{|l|}{ CCT $(\boldsymbol{\mu m})$} & \multicolumn{2}{l|}{ IOP $(\mathbf{m m H g})$} \\
\cline { 3 - 8 } & & Range & Mean & SD & Range & Mean & SD \\
\hline Blacks & $\begin{array}{l}\text { Males } \\
(N=50)\end{array}$ & $442-642$ & 513.2 & 41.3 & $10-21$ & 14.0 & 2.4 \\
\cline { 2 - 8 } & $\begin{array}{l}\text { Females } \\
(N=50)\end{array}$ & $443-583$ & 511.6 & 36.7 & $9-21$ & 13.6 & 2.8 \\
\hline Indians & Males & $442-598$ & 520.1 & 39.0 & $9-20$ & 15.0 & 2.8 \\
& $(N=50)$ & & & & & & \\
\cline { 2 - 8 } & Females & $470-607$ & 533.0 & 34.7 & $10-22$ & 15.7 & 2.9 \\
& $(N=50)$ & & & & & & \\
\hline
\end{tabular}

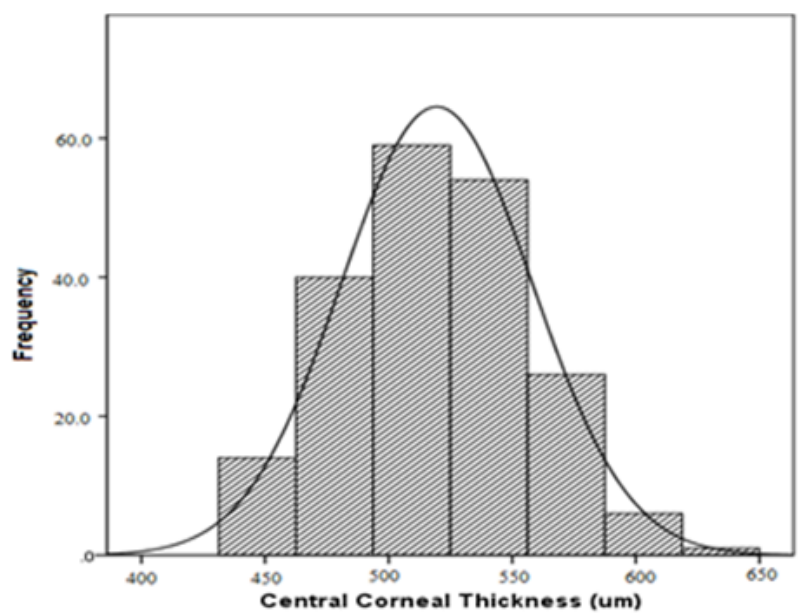

Figure 1: Histograms showing the distribution of CCT of the subjects $(N=200)$. The mean CCT of the population was $519.5 \mu \mathrm{m}$.

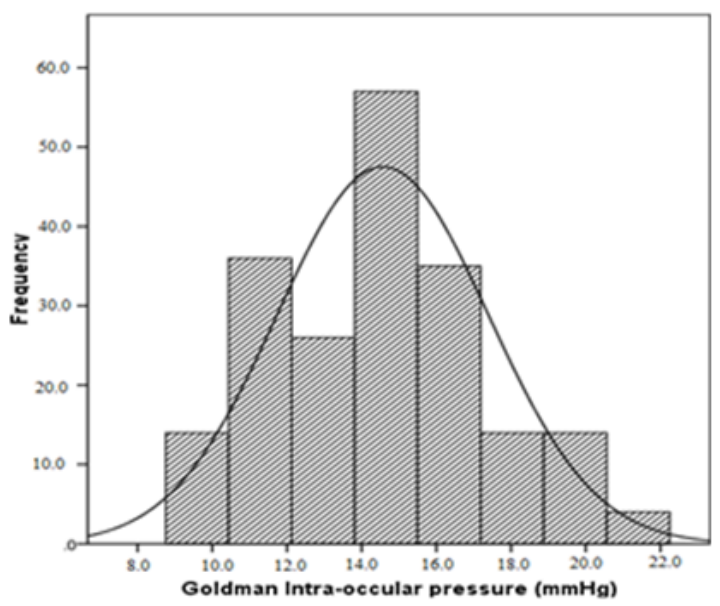

Figures 2: Histograms showing the distribution of IOP of the subjects $(N=200)$. The mean IOP of the population was $14.6 \mathrm{mmHg}$.

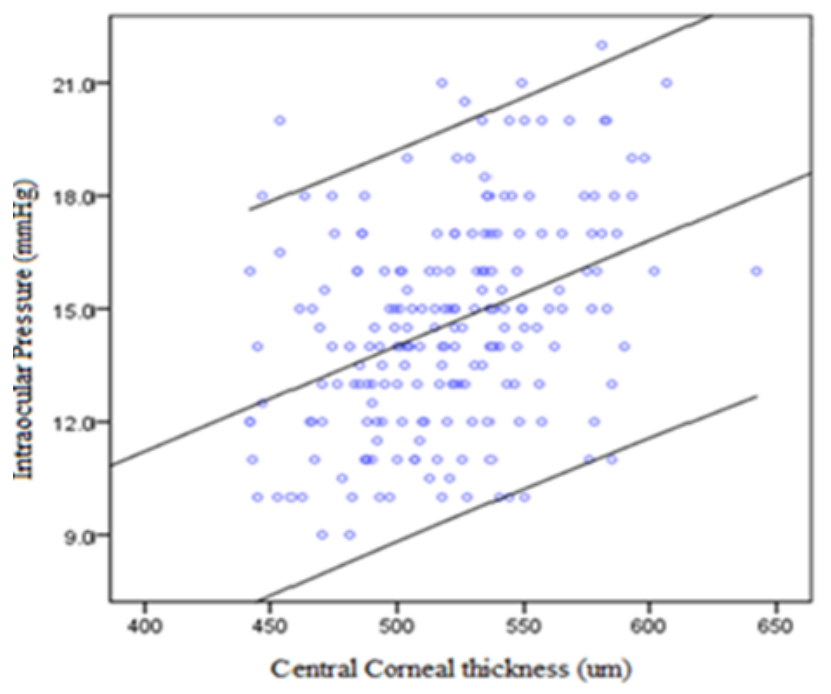

Figure 3: Scatter plot showing the correlation of CCT and IOP of in all the participants with $95 \%$ confidence interval of the regression line. $\left(R^{2}=0.146, r=0.382, p<0.001\right)$. The regression line shows IOP $=0.028 \mathrm{CCT}+0.019$. 


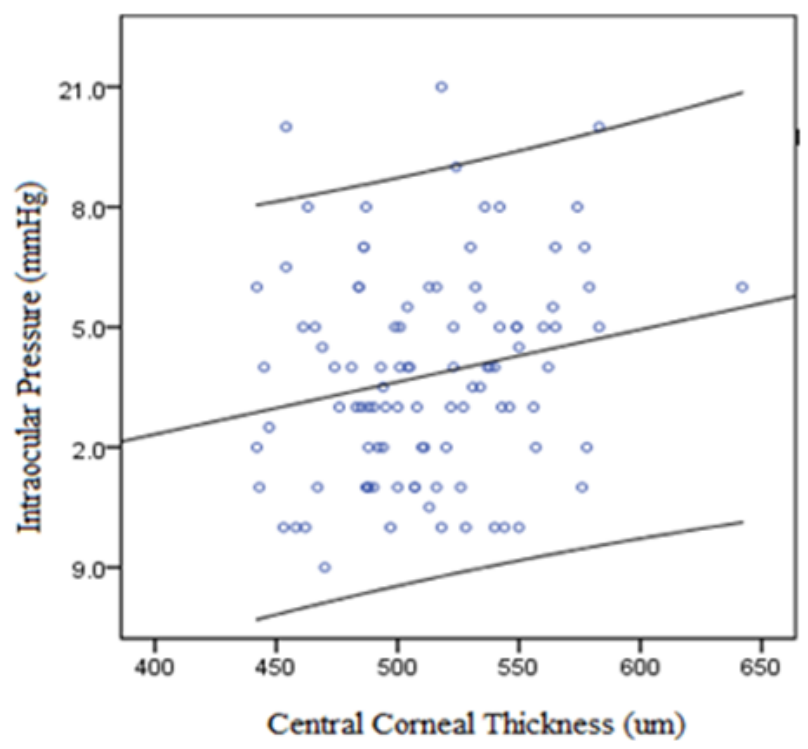

Figure 4: Scatter plot showing the correlation of CCT and IOP of the Black subjects with $95 \%$ confidence interval of the regression line. $\left(R^{2}=0.304, r=0.196, p=0.05\right)$. The regression line represents IOP $=0.013 \mathrm{CCT}+7.094$.

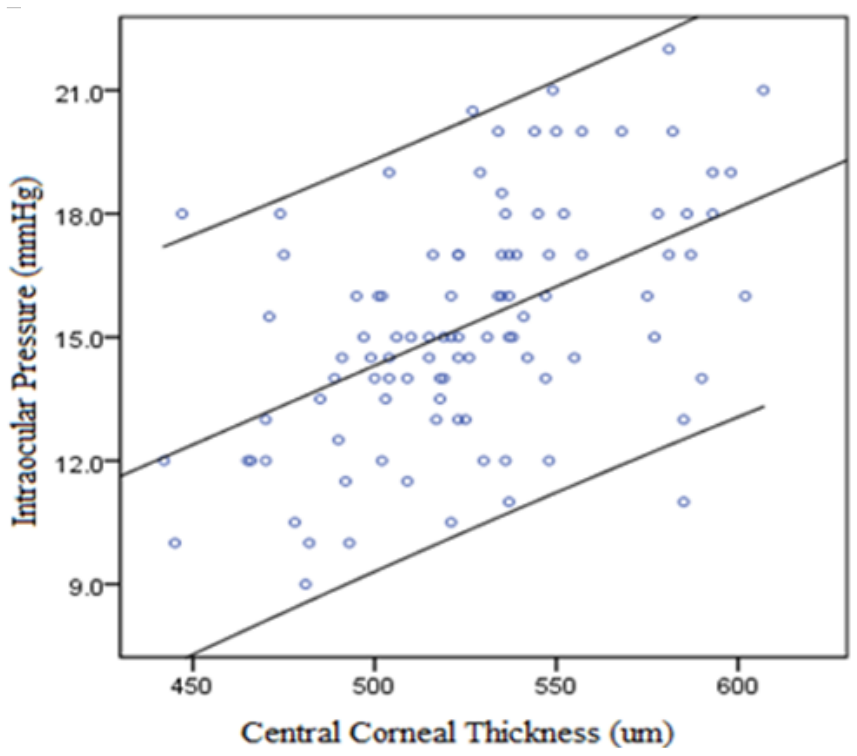

Figure 5: Scatter plot showing the correlation of CCT and IOP of the Indian subjects with $95 \%$ confidence interval of the regression line. $\left.R^{2}=0.248, r=0.498, p=0.001\right)$. The regression line represents IOP $=0.038 \mathrm{CCT}-4.884$.

\section{Discussion}

Ethnic variations in CCT and IOP have been reported in many race groups $3,9,10,15$, however, such variation has not been reported in the South African ethnic groups. This study established that the mean CCT values were greater in Indians than in Blacks, thereby supporting earlier reports $3,9,10,15$ that there is racial variation in CCT. The mean CCT of the Blacks was lower than those reported in other Black populations ${ }^{3,7-11}$ and the CCT of the Indians were lower than those reported previously in Asian populations $5,13,16$. Findings suggest that Black and Indian South Africans may have lower CCT values than other similar ethnic populations; therefore one could expect the IOP values in the South Africans to be less than those of other similar ethnic populations which may result in a delayed diagnosis of glaucoma. However, a study with greater sample size is needed to draw a firm conclusion.

Although, gender variations in CCT have been reported by previous authors and most authors (Hassan et $a l^{2}$, Shimmyo et $a l^{3}$, Godar ${ }^{5}$, Eballe et $a l^{7}$, Mercieca et $a l^{9}$ and Iyamu and Osuobeni17) found higher CCT values in males compared to females, Gelaw et $a l^{11}$ found no significant gender differences in CCT values. In the present study, thicker mean cornea (Table 2) was found in the females than in males, however, the difference was not statistically significant in the total population ( $p=0.51)$ or among the Blacks $(p=0.83)$ and Indians $(p=0.09)$. The CCT of the Indian females were statistically higher than those of the Black females $(p=0.003)$, thereby giving credence to gender variation. The higher CCT values in females in this study agrees with the report by Eysteinsson et al ${ }^{18}$, however, it is contrary to the previous findings in which higher mean was found in males $2,3,5,7-9,17$. There remains a need for more studies focusing on gender differences in CCT in different race groups in order to establish the reality of gender variation in CCT.

The IOP values of the Indians being higher than those of the Blacks (Table 1) could be attributed to the thicker corneas found in Indians compared to the Blacks. Although in the total population, higher IOP values were found in females than in males, the difference was not significant $(p=0.31)$. However, a significant difference in IOP values was found between the Indian females and Black females $(p<$ $0.001)$ but not Black and Indian males $(p=0.07)$. These values relate directly to the CCT and gender relationships in this study. Therefore, the gender difference in IOP found in the total population could be attributed to the significantly higher CCT values in the Indian females than the Black females.

The mean IOP value of the Indian population (15.3 
$\mathrm{mmHg}$ ) in this study was higher than those reported previously in other Asian populations: $12.9 \mathrm{mmHg}$ in a Pakistani population ${ }^{2}, 14.7 \mathrm{mmHg}$ in AmericanAsians $^{3}$ and $13.3 \mathrm{mmHg}$ in a Nepalese ${ }^{5}$ population. The study samples in all of these studies had higher mean ages than in this population and since IOP increases with an increase in age ${ }^{20}$, it is unexpected that lower mean IOP values were found in the present study.

The mean IOP value in this study is greater in the Black males $(14.0 \mathrm{mmHg})$ than in the Black females $(13.6 \mathrm{mmHg}),(p=0.46)$ which is in agreement with the findings of Shimmyo et $a l^{3}$ in an African American population. Also, the Indian females had higher IOP values than Indian males, however, the difference was not statistically significant $(p=0.20)$ which was similar to that found by Nemesure ${ }^{12}$ in the Barbados Eye Study. The gender differences in IOP in the present study could be attributed to the gender differences in the CCT.

Significant correlation between CCT and IOP has been reported by several authors $2,3,5,7,11$, however, Iyamu et $a l^{8}$, Gelaw et $a l^{11}$ and Marjanović ${ }^{19}$ found no significant association between the two values. In the present study, although there was a positive correlation between CCT and IOP, the association was weak and inconsistent being, $r=0.38, r^{2}=0.24(p$ $<0.001)$ in the total population; $r=0.498, r^{2}=0.24$ $(p<0.001)$ in the Indians and $r=0.196, r^{2}=0.039$ $(p=0.050)$ in the Blacks. This correlation showed that about $24 \%$ of the variations found in IOP among the total population and Indians were due to variations in CCT. Contrarily, the correlation accounts for only about $4 \%$ of the variation found in IOP in the Blacks. Similarly, the gender-related correlation between the CCT and IOP $\left(r=0.42, r^{2}=0.18, \mathrm{p}<\right.$ $0.001)$ in females and $\left(r=0.34, r^{2}=0.12, p<0.001\right)$ in the males were weak, indicating $18 \%$ and $12 \%$ respectively of the variations in IOP being due to gender-related CCT. The CCT-IOP correlation in relation to race being greater than in relation to gender in this study suggests that race has a greater impact than gender on the relationship between CCT and IOP. It is reckoned that a study with larger sample size is needed to draw firm conclusions in the relationships between CCT and IOP found in this study.

\section{Limitations and recommendations}

A major limitation of this study is the small sample size. Also, the study was conducted among University students with a narrow age group. Furthermore, the study did not include all South African ethnic groups. These factors limit the generalization of the findings to the provincial or national population. Therefore, it is recommended that a larger sample, with extended age groups and including other South African major ethnic groups should be included in a future study seeking to establish relationships between CCT and IOP. In spite of these limitations, this study has merit in providing baseline data on the racial and gender relationships in CCT and IOP.

\section{Conclusion}

Findings in this study agree with previous reports that there are racial differences in CCT and IOP values. Gender-related differences were also observed; however, in most cases they were not statistically significant. The mean CCT and mean IOP values of Black South Africans were lower than those of Indians and the mean CCT of the females was higher than that of the males. Also, in general, findings agree with previous studies that there is an association between CCT and IOP. There remains a need for a large population sample study of this topic for all the different South African ethnic groups.

\section{Acknowledgements}

We would like to thank participants who, in spite of their busy schedules created time to participate in this study.

\section{References}

1. World Health Organization. Glaucoma is the second leading cause of blindness globally. Bulletin of the World Health Organization. http: //www.who.int /bulletin /volumes /82/11/ feature1104 /en/ 2004 (Accessed on 03/03/2011).

2. Hassan M, Rehman A, Abbas M, Fawad, Bhatti N, Daud A. Relationship between central corneal thickness and intraocular pressure in selected Pakistani population. Pak J Ophthalmol 201026 79-82.

3. Shimmyo PN, Ross AJ, Moy A, Mostafavi R. Intraocular pressure, Goldmann applanation tension, corneal thickness, 
and corneal curvature in Caucasians, Asians, Hispanics and African-Americans. Am J Ophthalmol 2003136 603-613.

4. Casson RJ, Abraham LM, Newland HS, Muecke J, Sullivan T, Selva D, Aung T. Central corneal thickness and intraocular pressure in a non-glaucomatous Burmese population: The Meiktila Eye Study. Arch Ophthalmol 2008126 981985.

5. Godar ST, Kaini KR, Khattri JB. Factors affecting the central corneal thickness in Nepalese population. Nepal J Med Sci 20121 7-10.

6. Mohamed NY, Nour HM, Hassan MN, Ali NAM, Binnawi KH. Central corneal thickness in Sudanese population. Sudanese J Ophthalmol 20091 29-32.

7. Eballe AO, Koki G, Ellong A, Owono D, Epee E, Bella LA, Mvogo CE, Couam JM. Central corneal thickness and intraocular pressure in the Cameroonian non-glaucomatous population. Clin Ophthalmol 20104 717-724.

8. Iyamu E, Kio F, Idu IF, Osademe B. The relationship between central corneal thickness and intraocular pressure in adult Nigerians without glaucoma. Sierra Leone J Biomed Res 20102 95-102.

9. Mercieca K, Odogu V, Fiebai B, Arowolo O, Chukwuka F. Comparing central corneal thickness in a Sub-Sahara cohort to African-Americans and Afro-Caribbeans. Cornea 2007 26 557-560.

10. Nemesure B, Wu S, Hennis A, Leske MC. Corneal thickness and intraocular pressure in the Barbados eye studies. Arch Ophthalmol 2003121 240-244.

11. Gelaw Y, Kollmann M, Irungu NM, Ilako DR. The influence of central corneal thickness on intraocular pressure measured by Goldmann applanation tonometry among selected Ethiopian communities. J Glaucoma 201019 514-518.

12. Dueker DK, Singh K, Lin SC, Fechtner RD, Samples JR, Schuman JS. Corneal thickness measurement in the management of primary open-angle glaucoma. Ophthalmol 2007114 1779-1787.

13. Vijaya L, George R, Baskaran M, Arvind H, Raju P, Ve Ramesh S, Kumaramanickavel G, McCarty C. Prevalence of primary open-angle glaucoma in an urban South Indian population and comparison with a rural population: The Chennai Glaucoma Study. Ophthalmol 2008115 648-654.

14. Mashige KP, Rampersad N, Jhetam S, Govender P. Short-term variation in central corneal thickness and intraocular pressure using the Tono-Pachymeter NT530P (TonopachyTM). S Afr Optom 201271 12-21.

15. Villagas VM, Díaz L, Emanuelli A, Izguierdo NJ, Townsend W. Central corneal thickness and intraocular pressure in Puerto Rican glaucoma patients. Puerto Rico Health Sci J 200726 23-27.

17. Nangia V, Jonas JB, Sinha A, Matin A, Kulkarni M. Central corneal thickness and its association with ocular and general parameters in Indians: The Central India Eye and

18. Medical Study. Ophthalmol 2010117 705-10.

Iyamu E, Osuobeni E. Age, gender, corneal diameter, corneal curvature and central corneal curvature in Nigerians with normal intraocular pressure. J Optom 20125 87-97.
19. Eysteinsson T, Jonasson, Fasaki H, Arnarsson A, Sverrissonv T, Sasaki K, Stefánsson E. Central corneal thickness, radius of the corneal curvature and intraocular pressure in

20. normal subjects using non-contact techniques, Reykjavik Eye Study. Acta Ophthalmol 200280 11-15.

Marjanović I, Kontić D, Hentova-Sencanić P, Marković V, Božć M. Correlation between CCT and IOP in various age groups. Srp Arch Celok Lek 2010130 279-286.

Wong TT, Wong TY, Foster PJ, Crowston JG, Fong C, Aung $\mathrm{T}$. The relationship of intraocular pressure with age, systolic blood pressure, and central corneal thickness in an Asian population. Invest Ophthalmol Vis Sci 200950 4097-4102. 